\title{
Changes in corneal parameters at confocal microscopy in treated glaucoma patients
}

This article was published in the following Dove Press journal:

Clinical Ophthalmology

25 July $201 \mathrm{I}$

Number of times this article has been viewed

\author{
Stefano Ranno' \\ Paolo Fogagnolo 2 \\ Luca Rossetti ${ }^{3}$ \\ Nicola Orzalesi ${ }^{3}$ \\ Paolo Nucci' \\ 'Eye Clinic, San Giuseppe Hospital, \\ University of Milan, Milan, Italy; \\ ${ }^{2}$ GB Bietti Foundation for Study \\ and Research in Ophthalmology, \\ Rome, Italy; ${ }^{3}$ Eye Clinic, Department \\ of Medicine, San Paolo Hospital, \\ University of Milan, Milan, Italy
}

Correspondence: Stefano Ranno Via San Vittore 12, Milan, Italy Tel/Fax +39028599 4974

Email stefanoranno@yahoo.it
Background: The purpose of this study was to evaluate corneal parameters in treated glaucoma patients, nontreated glaucoma patients, and normal subjects using confocal microscopy.

Methods: Forty patients with primary open-angle glaucoma and 22 untreated controls underwent confocal microscopy of the cornea using the Heidelberg retinal tomograph cornea module. The glaucoma group was divided into two subgroups, ie, patients on medical treatment for at least two years before inclusion (with beta-blockers or prostaglandin analogs) and nontreated glaucoma patients. The following corneal parameters were evaluated: endothelial cell density and number, reflectivity, and tortuosity of sub-basal nerves. For reflectivity and tortuosity, a dedicated grading scale ranging from 0 to 4 was used. Differences between treatments were also evaluated in the treated glaucoma group.

Results: Number of fibers and reflectivity of the sub-basal plexus were significantly lower in glaucoma patients as compared with controls $(2.5 \pm 0.7$ versus $2.9 \pm 0.9, P=0.006$, and $2.3 \pm 0.8$ versus $2.7 \pm 0.9, P=0.04$, respectively), whereas tortuosity was significantly higher $(2.6 \pm 1$ versus $2.0 \pm 0.8, P=0.007$ ). Endothelial cell density (measured as cells per $\mathrm{mm}^{2}$ ) was lower in the glaucoma group comparing treated patients with nontreated patients $(2826 \pm 285$ versus $3124 \pm 272, P=0.0003)$. Comparing treated patients with nontreated patients, relevant differences were found in number $(2.3 \pm 0.7$ versus $2.8 \pm 0.8, P=0.004)$, tortuosity $(2.8 \pm 1$ versus $2.2 \pm 0.8, P=0.004)$, and reflectivity $(2.2 \pm 0.8$ versus $2.6 \pm 0.8, P=0.04)$. No differences in corneal parameters were found between beta-blockers and prostaglandin analogs.

Conclusion: This study shows that differences in corneal parameters between glaucoma patients and controls may be due to the medical treatments used for glaucoma. These data should be taken into consideration in long-standing medical glaucoma treatment and in potential candidates for surgery.

Keywords: cornea, glaucoma, sub-basal nerves, endothelial cells, confocal microscopy

\section{Introduction}

Glaucoma is an optic neuropathy characterized by structural changes and functional impairment. It can be divided into primary open-angle glaucoma, which has an insidious and slow onset, and angle-closure glaucoma. Quigley and Broman ${ }^{1}$ estimate that glaucoma affects 60.5 million people worldwide and that this number will increase to about 80 million by 2020 . Approximately $75 \%$ of these patients will have primary open-angle glaucoma. Glaucoma is the second leading cause of blindness in the world and would account for over eight million cases of blindness today, rising to over 11 million by $2020{ }^{1}$

Treatments for glaucoma aim at reducing intraocular pressure, which is the main risk factor for development and progression of the disease. Medical, surgical, and 
laser options are available. Topical medical treatments are effective in most cases. Even if monodose treatments are available for beta-blockers and, very recently, for prostaglandin analogs, multidose treatments are more frequently used. Multidose formulations require the use of a preservative in order to guarantee the absence of contamination by microorganisms. Unfortunately, this toxic effect is aspecific and generates dose-dependent noxious effects on the ocular surface.

Glaucomatous patients often need to use more than one eye drop to obtain adequate reduction in intraocular pressure, and topical therapy is carried on for many years or lifelong, so adverse events and side effects should be minimized to achieve optimal compliance. Therefore, ocular surface impairment in glaucoma has become a topic of great interest. The negative effects of glaucoma medications may be due to both allergic and toxic mechanisms in the conjunctiva, lacrimal film, and cornea. ${ }^{2}$ These effects may be due to the active component, as well as to preservatives, but the exact mechanisms involved in inducing toxic or proinflammatory effects of ophthalmic solutions are still unknown. ${ }^{3}$ Among the side effects, ocular surface disorders attributable to the drug itself or to drug preservatives are relatively common. ${ }^{4-9}$ Furthermore, the use of antiglaucoma drugs may induce cytotoxicity in corneal endothelial cells, as shown by in vitro studies. $^{10,11}$

Confocal microscopy is a novel diagnostic technique which provides noninvasive optical sectioning of the tissues of the anterior segment of the eye and allows high-magnification imaging of the corneal epithelium, Bowman's membrane, stromal keratocytes, and nerves, as well as the corneal endothelium. Confocal imaging is able to show changes on the ocular surface in a number of subclinical eye conditions. ${ }^{12-15}$ The aim of this study was to investigate with confocal microscopy in vivo the subbasal corneal plexus and endothelial cell involvement in medical treatment of glaucoma.

\section{Materials and methods}

\section{Patients}

This study was conducted at the Eye Clinic of the University of Milan, San Paolo Hospital, Milan, Italy, was approved by the local ethics committee, and adhered to the tenets of the Declaration of Helsinki. Informed consent was obtained from all patient before enrolment.

Caucasian patients with primary open-angle glaucoma referred to the glaucoma service from April 2009 to October 2009 were considered for the study. Inclusion criteria were a diagnosis of glaucoma defined by glaucomatous optic disc changes and corresponding visual field defects, based on the European Glaucoma Society Guidelines criteria. ${ }^{16}$ Only patients with intraocular pressure not over $24 \mathrm{mmHg}$ on repeated measurements were enrolled. Glaucoma patients were divided into two subgroups, ie, patients who had had medical treatment (with beta-blockers or prostaglandin analogs) for at least two years before inclusion and nontreated glaucoma patients. Exclusion criteria were ocular trauma, corneal changes of any kind, media opacities, history of ocular surgery other than for uncomplicated cataract, current use of contact lens, and autoimmune disease. Forty consecutive patients who fulfilled the inclusion and exclusion criteria and 22 normal subjects were enrolled in the study.

\section{Study procedures}

A medical history was taken for all the participants. All the subjects underwent a complete ophthalmic examination, including anterior segment biomicroscopy and fundus examination, refraction, and measurement of best corrected visual acuity using the Early Treatment of Diabetic Retinopathy Study chart. In vivo laser scanning confocal microscopy of the cornea was performed using the Heidelberg Retina Tomograph 2-Rostock cornea module (Heidelberg Engineering, Dossenheim, Germany). Data were collected for both eyes, and one eye for each patient was chosen at random (unless only one eye met the inclusion criteria) for analytical purposes.

\section{In vivo laser confocal microscopy of cornea}

The Heidelberg retina tomograph (HRT) was initially designed to evaluate the optic nerve head in glaucoma. The second HRT version, endowed with a lens system, known as the Rostock cornea module (RCM), allows in vivo confocal study of the cornea layers. ${ }^{17}$ The laser source used in the RCM is a diode laser with a wavelength of $670 \mathrm{~nm}$. The two-dimensional images acquired have a definition of $384 \times 384$ pixels over an area of $400 \mu \mathrm{m} \times 400 \mu \mathrm{m}$, with lateral digital resolution of $1 \mu \mathrm{m} / \mathrm{pixel}$ and a depth resolution of $2 \mu \mathrm{m} /$ pixel.

\section{Data collection}

After administration of one drop of $0.4 \%$ oxybuprocaine (Novesine $^{\circledR}$; MSD-Chibret, Paris, France) and one drop of a lubricant gel, $0.2 \%$ carbomer (Lacrigel $^{\circledR}$; Europhtha, Monaco) the patient was asked to fixate on a small bright red light while the examination was performed in the 
contralateral eye. Correct alignment and contact with the cornea were monitored using the images captured by a camera tangential to the eye. The distance from the cornea to the microscope was kept stable using a single-use contact element in sterile packaging (TomoCap ${ }^{\circledR}$; Heidelberg), which is a thin cap with a planar contact surface made from polymethyl methacrylate and is coupled optically to the lens with the aid of a gel.

A scan of the full thickness of the cornea was performed along the optical axis, and no tangential movements were allowed in order to prevent biased acquisitions. The examination took about three minutes per eye and about 120 images were collected. Only images of the center of the cornea were collected. The best-focused sub-basal plexus and endothelial cell images were considered for the analysis.

The following parameters of the sub-basal plexus nerves were considered: number per frame, and tortuosity and reflectivity of fibers. The last two parameters were evaluated by comparison with the reference images according to the method proposed by Oliveira-Soto and Efron, and graded from 0 to $4 .^{18}$ The HRT Rostock cornea module also has a semi-automated system for endothelial cell counting. On the best focused endothelial cell image, a region of interest is selected, cells are marked, and the system automatically calculates cell density.

\section{Agreement}

All study examinations were performed by a single masked expert operator (SR). Before the study began, the reproducibility of data was tested using the following procedure. The evaluator collected five scans of the plexus of a volunteer along the corneal axis, and during the same day, at intervals of 60 minutes and at the end of each acquisition, selected the best-focused image of the plexus. Masking was obtained by an independent investigator mixing these five images with 10 control images, and the operator was asked to grade all images considering number, tortuosity, and reflectivity of fibers. For each parameter, agreement of the five images was defined in the presence of values within \pm 1 of the mean value, this cutoff value being derived from previous studies on corneal confocal microscopy. ${ }^{18}$ Intraobserver agreement for image scores were calculated using the intraclass correlation coefficient as follows:

\section{Intraclass correlation coefficient $=\sigma \mathrm{a}^{2} /\left(\sigma^{2}+\sigma \mathrm{a}^{2}\right)$}

where $\sigma^{2}=\mathrm{QM}(\mathrm{e})$, or intraclass variability: $\sigma \mathrm{a}^{2}=[\mathrm{QM}(\mathrm{a})-$ $\mathrm{QM}(\mathrm{e})] / \mathrm{n}$ or (interclass - intraclass variability)/number of classes. ${ }^{19}$ Agreement was defined according to the guidelines proposed by Landis and Koch: ${ }^{20}$ chance agreement, 0.01-0.19; poor agreement, 0.20-0.39; fair agreement, 0.40-0.59; moderate agreement, 0.60-0.79; and substantial agreement, 0.80-1.00. For our series of data, agreement was 0.70 for tortuosity, 0.75 for reflectivity, and 0.9 for number of fibers.

\section{Statistical analysis}

Intergroup differences were evaluated using the $t$-test for unpaired data. Differences with $P<0.05$ were deemed to be statistically significant. All statistical analyses were calculated using the SPSS (version 15.0, SPSS Inc, Chicago, IL).

\section{Results}

The demographic characteristics of the patients are summarized in Table 1. Mean age and gender were not significantly different between the glaucoma patients and controls ( $P=0.18, t$-test, and $P=0.80, X^{2}$, respectively).

The numbers of nerve fibers $(2.5 \pm 0.7$ versus $2.9 \pm 0.9$, $P=0.006)$ and reflectivity of fibers $(2.3 \pm 0.8$ versus $2.7 \pm 0.9$, $P=0.04)$ of the sub-basal plexus were significantly lower in glaucoma patients as compared with controls, whereas tortuosity was significantly higher $(2.6 \pm 1$ versus $2.0 \pm 0.8, P=0.007$, Figure 1). Endothelial cell density (given as cells $/ \mathrm{mm}^{2}$ ) was lower in the glaucoma group $(2925 \pm 313$ versus $3187 \pm 312$, $P=0.0003)$.

Table I Demographics of study participants

\begin{tabular}{|c|c|c|c|c|c|}
\hline & $\begin{array}{l}\text { A normal } \\
\text { subjects }\end{array}$ & $\begin{array}{l}\text { B glaucoma } \\
\text { patients }\end{array}$ & B I beta-blockers & $\begin{array}{l}\text { B2 prostaglandin } \\
\text { analogs }\end{array}$ & $\begin{array}{l}\text { B3 nontreated } \\
\text { glaucoma patients }\end{array}$ \\
\hline Subjects (n) & 22 & 40 & 12 & 12 & 16 \\
\hline Age, years (SD) & $62.5 \pm 8$ & $62.5 \pm 6$ & $61.5 \pm 6$ & $63.5 \pm 6$ & $62.6 \pm 5$ \\
\hline Gender & $10 \mathrm{~F}, 12 \mathrm{M}$ & $20 \mathrm{~F}, 20 \mathrm{M}$ & $7 \mathrm{~F}, 5 \mathrm{M}$ & $6 \mathrm{~F}, 6 \mathrm{M}$ & $7 \mathrm{~F}, 9 \mathrm{M}$ \\
\hline IOP, mmHg (SD) & $17.1 \pm 2.0$ & $18.3 \pm 2.4$ & $18.2 \pm 1.9$ & $18.4 \pm 2.8$ & $22.3 \pm 2.6$ \\
\hline Refraction, diopters (SD) & $-1.35 \pm 1.49$ & $-1.30 \pm 1.20$ & $-1.28 \pm 2.10$ & $-1.30 \pm 1.75$ & $-1.31 \pm 1.23$ \\
\hline CCT $(\mu \mathrm{m})$ & $553 \pm 20$ & $548 \pm 23$ & $548 \pm 27$ & $550 \pm 24$ & $546 \pm 25$ \\
\hline
\end{tabular}

Abbreviations: SD, standard deviation; IOP, intraocular pressure; CCT, central corneal thickness; F, female; M, male. 

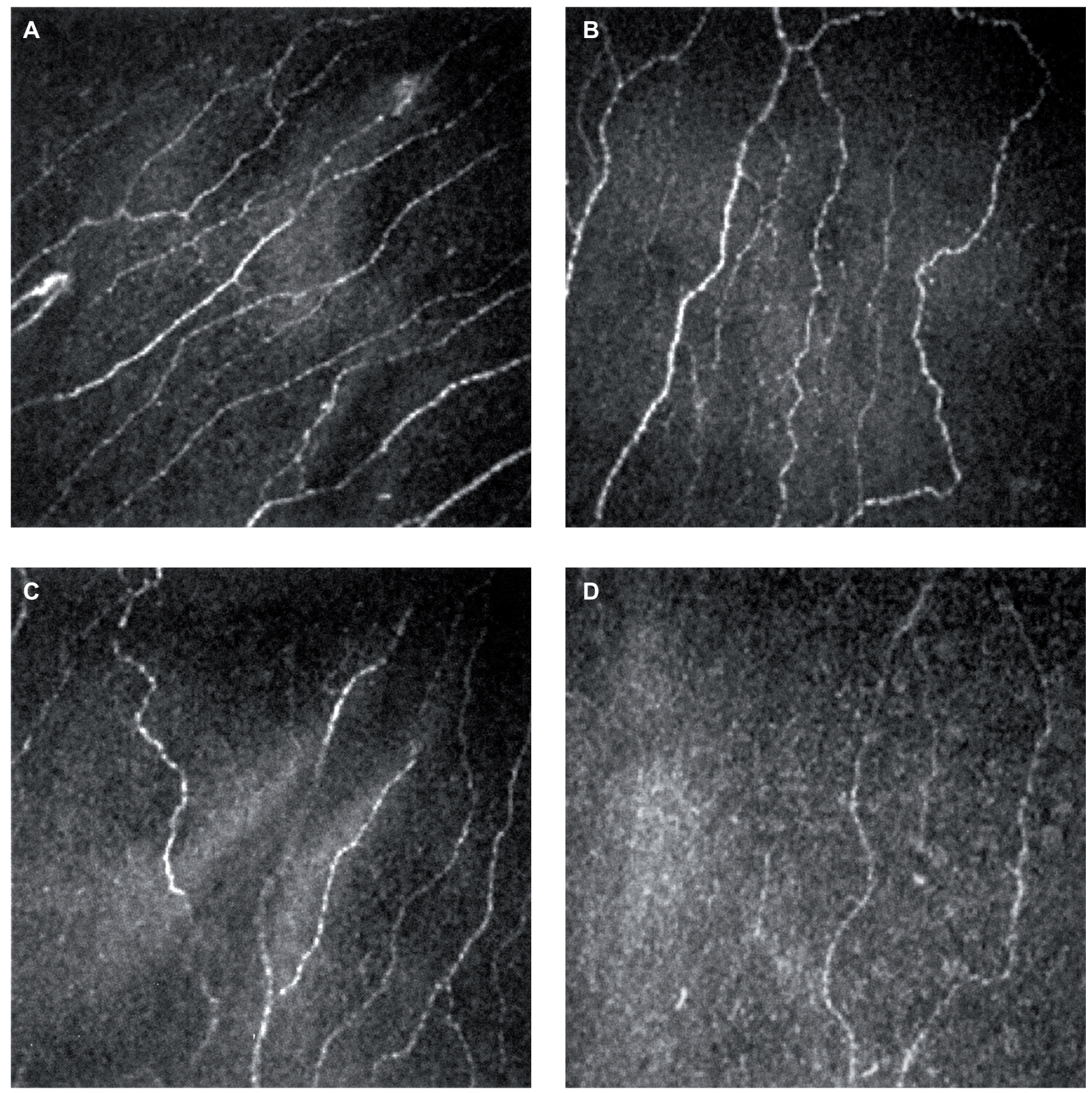

Figure I Subbasal nerves plexus of normal subject (A), nontreated glaucoma patient (B), prostaglandin analog treated patient (C) and beta-blocker treated patient (D).

Comparing treated and untreated glaucoma patients, significant differences were found in nerve fiber number ( $2.3 \pm 0.7$ versus $2.8 \pm 0.8, P=0.004)$, tortuosity $(2.8 \pm 1$ versus $2.2 \pm 0.8, P=0.004)$, reflectivity $(2.2 \pm 0.8$ versus $2.6 \pm 0.8, P=0.04)$, and endothelial cell density $(2826 \pm 285$ versus $3124 \pm 272, P=0.0004)$. No differences were found between prostaglandin analogs and beta-blockers for nerve number $(P=0.8)$, tortuosity $(P=1)$, reflectivity $(P=0.9)$, or number of endothelial cells $(P=0.9)$. Normal subjects and untreated glaucoma patients had similar numbers $(P=0.5)$, tortuosity $(P=0.5)$, and reflectivity $(P=0.6)$ of nerve fibers and endothelial cell counts $(P=0.4)$.

\section{Discussion}

Several studies have demonstrated that long-term use of intraocular pressure-lowering treatments frequently cause chronic changes on the ocular surface ${ }^{6,15}$ due to the drug itself or to preservatives. ${ }^{6,20}$ Benzalkonium chloride is the most commonly used preservative in ophthalmic preparations. It is a quaternary ammonium compound with potent antimicrobial effects, but also with relevant dose-dependent side effects on the cornea and conjunctiva. ${ }^{21,22}$ Due to these characteristics, it has been suggested that benzalkonium chloride be considered as an active compound, the concentration of which should be specified for the product (a fact that, to date, is 
not compulsory in many countries, including Italy). Current intraocular pressure-lowering treatments have benzalkonium chloride concentrations ranging from $0.01 \%$ to $0.005 \%$, even if the recommended concentration is less than $0.005 \%{ }^{22}$ Other less toxic preservatives have been studied and are now clinically available in the glaucoma field, ie, SofZia ${ }^{\circledR}$ (Alcon Inc. Hünenberg, Switzerland), Purite ${ }^{\circledR}$ (Allergan, Inc. Irvine, CA), ${ }^{23}$ and Poliquad ${ }^{\circledR}$ (Alcon Inc. Hünenberg, Switzerland). It has been suggested that inflammatory mechanisms combining allergy with toxicity are involved in the complexity of reactions occurring at the ocular surface in patients using preserved topical glaucoma treatments. ${ }^{2}$

The recent introduction of confocal microscopy allows clinical insights at cellular levels, which was impossible with traditional in vivo diagnostics used in clinical practice. In this study, we performed a confocal examination of the cornea in glaucoma patients receiving intraocular pressure-lowering treatments for at least two years, compared with untreated glaucoma patients and controls, and showed that treated patients had relevant changes in systolic blood pressure and endothelial cell density.

Nerve fibers are important for corneal trophism and for maintaining a healthy ocular surface. ${ }^{24}$ A lower nerve density may impair corneal sensitivity, as observed in glaucoma patients. ${ }^{25}$ Overall, our data confirm the findings by Martone et $\mathrm{al}^{26}$ who showed a decrease in number of nerve fibers and an increase in tortuosity at confocal microscopy in treated glaucoma patients compared with controls. Compared with that study, we found differences in corneal parameters in the control group $(2.9 \pm 0.9$ versus $5.26 \pm 1.3$ and $2.0 \pm 0.8$ versus $1.2 \pm 0.39)$ for number of nerves and tortuosity, respectively, as in the glaucoma group. These findings may be due to differences in the study populations (most likely due to the higher duration of therapy in our study), and also to the poor interobserver reproducibility of confocal microscopy. Also, a lower fiber reflectivity was found in our glaucoma group, which may be due to the absence of correction for reflectivity of Bowman's membrane.

The second confocal parameter evaluated in this study was endothelial cell density. It has been shown that corneal endothelial cell survival, after chronic exposure to commercially available eye drops, is longer in the absence of a preservative. ${ }^{27}$ Even if there is some evidence that intraocular pressure-lowering treatments may damage or interfere with the normal physiologic functions of the corneal endothelium, ${ }^{28}$ the endothelial cell count was not considered in previous confocal studies. Our study is the first to show that a lower endothelium density is present in patients receiving antiglaucoma drugs by means of confocal microscopy.
A strength of this study was the inclusion of a group of untreated glaucoma patients, which allowed us to show that our untreated glaucoma patients and controls had similar corneal parameters, thus demonstrating that the corneal damage observed was not due to glaucoma itself but to the therapy used.

All confocal studies should be evaluated with caution given the limitations of this technique, ie, it is a qualitative and subjective examination, the reproducibility of which has not been fully explored. Also, we limited our investigations to the center of the cornea, and different results might be obtained by inspecting the corneal periphery.

In conclusion, this study confirms that, in addition to intraocular pressure-lowering effects, specific preserved topical glaucoma treatments induce changes at the ocular surface which can be well documented by means of confocal microscopy. In the balance between efficacy and tolerability, it must be kept in mind that formulations with low cytotoxicity (ie, low or absent concentrations of preservative, or containing preservatives less toxic than benzalkonium chloride) may guarantee fewer side effects, with higher tolerability and better compliance.

\section{Disclosure}

The authors report no conflicts of interest in this work.

\section{References}

1. Quigley HA, Broman AT. The number of people with glaucoma worldwide in 2010 and 2020. Br J Ophthalmol. 2006;90:262-267.

2. Baudouin $\mathrm{C}$, Liang H, Hamard $\mathrm{P}$, et al. The ocular surface of glaucoma patients treated over the long term expresses inflammatory markers related to both T-helper 1 and T-helper 2 pathways. Ophthalmology. 2008;115:109-115.

3. Wilson LA. To preserve or not to preserve, is that the question? $\mathrm{Br} J$ Ophthalmol. 1996;80:583-584.

4. Wilson FM. Adverse external ocular effects of topical ophthalmic medications. Surv Ophthalmol. 1979;24:57-88.

5. Sherwood MB, Grierson I, Millar L, et al. Long-term morphologic effects of antiglaucomatous drugs on the conjunctiva and Tenon's capsule in glaucoma patients. Ophthalmology. 1989;96:327-335.

6. Herreras JM, Pastor JC, Calonge M, et al. Ocular surface alteration after long-term treatment with an antiglaucomatous drug. Ophthalmology. 1992;99:1082-1088.

7. Ishibashi T, Yokoi N, Kinoshita S. Comparison of the short-term effects on the human corneal surface of topical timolol maleate with and without benzalkonium chloride. J Glaucoma. 2003;12:486-490.

8. Baudouin C. Side effects of antiglaucomatous drugs on the ocular surface. Curr Opin Ophthalmol. 1996;7:80-86.

9. Shimazaki J, Hanada K, Yagi Y, et al. Changes in ocular surface caused by antiglaucomatous eye drops: prospective, randomised study for the comparison of $0.5 \%$ timolol vs $0.12 \%$ unoprostone. Br J Ophthalmol. 2000;84:1250-1254

10. Wu KY, Wang HZ, Hong SJ. Cellular cytotoxicity of antiglaucoma drugs in cultured corneal endothelial cells. Kaohsiung J Med Sci. 2007;23:105-111. 
11. Ayaki M, Noda Y, Yaguchi S, et al. Cytotoxicity of antiglaucoma ophthalmic solutions for human corneal endothelial cells. Nippon Ganka Gakkai Zasshi. 2009;113:576-582. Japanese.

12. Villani E, Galimberti D, Viola F, Mapelli C, Ratiglia R. The cornea in Sjogren's syndrome: an in vivo confocal study. Invest Ophthalmol Vis Sci. 2007;48:2017-2022.

13. Villani E, Galimberti D, Viola F, Mapelli C, Del Papa N, Ratiglia R. Corneal involvement in rheumatoid arthritis: an in vivo confocal study. Invest Ophthalmol Vis Sci. 2008;49:560-564.

14. De Cillà S, Ranno S, Carini E, et al. Corneal subbasal nerves changes in patients with diabetic retinopathy: an in vivo confocal study. Invest Ophthalmol Vis Sci. 2009;50:5155-5158.

15. Ceresara G, Fogagnolo P, De Cillà S, et al. Corneal involvement in Crohn's disease: an in vivo confocal microscopy study. Cornea. 2011;30:136-142.

16. European Glaucoma Society. Terminology and guidelines for glaucoma. Savona, Italy: Editrice Dogma SRL; 2008.

17. Stave J, Zinser G, Grummer G, Guthoff R. Modified Heidelberg retinal tomography HRT: initial result of in vivo presentation of corneal structures. Ophthalmologe. 2002;99:276-280. German.

18. Oliveira-Soto L, Efron N. Morphology of corneal nerves using confocal microscopy. Cornea. 2001;20:374-384.

19. Fleiss JJ, Choen J. The equivalence of weighted kappa and the intraclass correlation coefficient as measures of reliability. Educ Psychol Meas. 1973;33:613-619.

20. Landis JR, Koch GG. The measurements of observer agreement for categorical data. Biometrics. 1977;33:159-174.
21. Brandt JD, Wittpen JR, Katz LJ, et al. Conjunctival impression cytology in patients with glaucoma using long-term topical medication. Am J Ophthalmol. 1993;112:297-301.

22. Becquet F, Goldschild M, Moldovan MS. Histopathological effects of topical ophthalmic preservatives on rat corneoconjunctival surface. Curr Eye Res. 1998;17:419-425.

23. De Saint JM, Debbash F, Brignole P. Toxicity of preserved and unpreserved antiglaucoma topical drugs in an in vitro model of conjunctival cells. Curr Eye Res. 2000;20:85-94.

24. Grant R, Ajello M, Vlass E. Salt water or high tech? a look at two new rising solutions for contact lenses. Optician. 1996;212:38-41.

25. Zhang M, Chen J, Luo L, Xiao Q, Sun M, Liu Z. Altered corneal nerves in aqueous tear deficiency viewed by in vivo confocal microscopy. Cornea. 2005;24:818-824.

26. Martone G, Frezzotti P, Tosi GM, et al. An in vivo confocal microscopy analysis of effects of topical antiglaucoma therapy with preservative on corneal innervation and morphology. Am J Ophthalmol. 2009; $147: 725-735$.

27. Ayaki M, Yaguchi S, Iwasawa A, Koide R. Cytotoxicity of ophthalmic solutions with and without preservatives to human corneal endothelial cells, epithelial cells and conjunctival epithelial cells. Clin Experiment Ophthalmol. 2008;36:553-559.

28. Waltman SR, Yarian D, Hart W, et al. Corneal endothelial changes with long-term topical epinephrine therapy. Arch Ophthalmol. 1977;95:1357-1358.
Clinical Ophthalmology

\section{Publish your work in this journal}

Clinical Ophthalmology is an international, peer-reviewed journal covering all subspecialties within ophthalmology. Key topics include: Optometry; Visual science; Pharmacology and drug therapy in eye diseases; Basic Sciences; Primary and Secondary eye care; Patient Safety and Quality of Care Improvements. This journal is indexed on

\section{Dovepress}

PubMed Central and CAS, and is the official journal of The Society of Clinical Ophthalmology (SCO). The manuscript management system is completely online and includes a very quick and fair peer-review system, which is all easy to use. Visit http://www.dovepress.com/ testimonials.php to read real quotes from published authors. 